\title{
Offsetting under pressure
}

\author{
Kevin Anderson, Deputy Director of the UK Tyndall Centre and an expert on greenhouse-gas emissions \\ trajectories explains to Nature Climate Change why he believes that carbon offsetting can be worse \\ than useless.
}

\section{What had you planned to present at the recent Planet Under Pressure conference in London?}

I was going to present a paper arguing that orthodox analyses of climate change mitigation drastically underplay the level of transformation necessary in our economy to meet the target of limiting warming to $2{ }^{\circ} \mathrm{C}$ above pre-industrial levels. In part it argues that "in 2012 with a legacy of inaction and rapidly rising emissions it is now difficult, if not impossible, to envisage anything other than a planned economic recession within the industrialized countries [defined as Annex 1 countries under the Kyoto Protocol] being compatible with $2{ }^{\circ} \mathrm{C}, 3^{\circ} \mathrm{C}$ and increasingly $4^{\circ} \mathrm{C}$ futures, particularly if some emissions space is to be available for non-Annex 1 nations to develop."

\section{Why did you decide not to attend?}

The conference organizers made a contribution to an offsetting fund compulsory for delegates. They will use this money to purchase 'emissions-reduction credits' from a carbon trader. But in my view, offsetting is worse than doing nothing. I reluctantly decided not to attend, as it would be hypocritical of me to purchase offset credits.

What are your objections to offsetting? The science underpinning climate change indicates that the temperature rise to be expected by around the end of this century (compared with pre-industrial levels) relates to the total quantity of emissions put into the atmosphere over the century. Consequently, when considering the impact of our activities we have to consider the total sum of our emissions released between 2000 and 2100, and the impact of offset projects must be measured over this period. There is no point in reducing emissions in the short-run by one tonne if the knock-on impact is two tonnes emitted in 2020 or even 1.5 tonnes in say 2050 . The implications of this for the concept of offsetting are profound. Implicit in the offsetters' claim to account for carbon leakage over the relevant timeframe are powers of prediction that could have foreseen the Internet and low-cost airlines following from Marconi's 1901

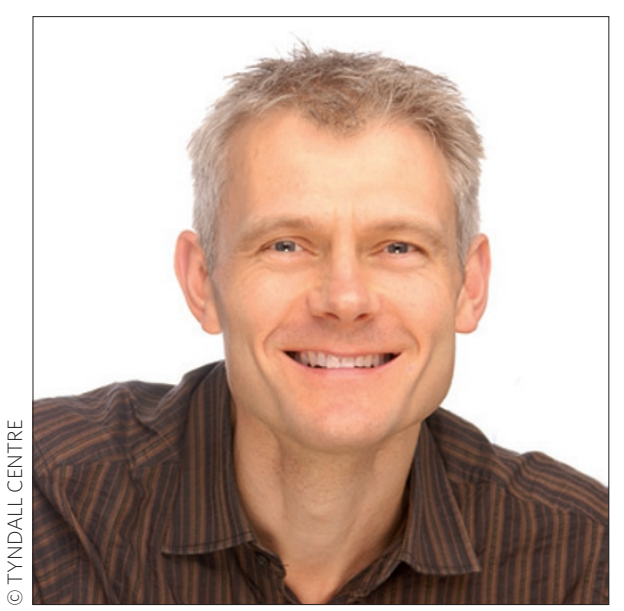

According to this pathway, their emissions peak by 2025 and then reduce at twice the rate that Stern and others say - wrongly in my view - is possible with economic growth. Such a pathway is just about viable and could, if allied with radical and immediate reductions from those of us in the Annex 1 nations, give an outside chance of not exceeding $2{ }^{\circ} \mathrm{C}$ above pre-industrial levels. No doubt many will say that such reductions are impossible - but is living with a $4^{\circ} \mathrm{C}$ or $5{ }^{\circ} \mathrm{C}$ future this century any less impossible?

Have you ever before declined to attend a conference?

Not on the basis of offsetting. However, I seldom attend major international events

telegraph and the Wright brothers' 1903 maiden flight.

\section{What are the alternatives?}

The main reason for offsetting in this case is air travel. I take the straightforward view that we need to identify and considerably reduce such high-emission activities. My concern is that this offset simply allows scientists to continue to consider highcarbon behaviours appropriate. Indeed, a number of colleagues have made this case to me, confident that their emissions were being 'neutralized'. The knock-on effect is that we make these behaviours socially acceptable and lend legitimacy to the 'pollute and offset' paradigm. Instead, we need to work hard at making virtual engagement and lower-carbon travel options available, however challenging this may be. For instance, the conference could have included travel advice or innovative registration tariffs rewarding lower-carbon involvement.

You believe that the developed world needs to reduce its emissions radically and pretty much instantaneously. What about the developing world?

A rise in emissions from the industrializing nations is, in the short term, a good indicator of rising prosperity and consequently should be welcomed. Our last Royal Society paper suggested a hugely demanding pathway from non-Annex 1 nations in which their existing rate of emission growth is almost halved. for a variety of reasons - important among these is that they typically involve, in my view, unjustifiably large carbon dioxide emissions. However, I also find they seldom offer significant new information that I couldn't easily get elsewhere and for a much lower carbon spend. They have a very large opportunity cost and are often intellectually less rewarding than 'local' discussions with researchers around the UK. They also add e-mails and new contacts to an already unmanageable e-mail backlog. While we've been busily engaging in evermore international climate jamborees, emissions have been rising out of control so they certainly haven't engendered wider mitigation. Attending international conferences, workshops and meetings is supposed to be good for an academic's status. This stimulates a self-perpetuating cycle of travel, as early career researchers feel compelled and are encouraged to attend such events. Personally, I am unconvinced by this argument, and believe that status should be premised on the robustness and integrity of our research rather than the number of air miles we clock up.

\section{INTERVIEW BY MARC HUDSON \\ Marc Hudson is co-editor of \\ Manchester Climate Monthly, http:// manchesterclimatemonthly.net. \\ e-mail:momonthly@gmail.com}

Published online: 15 April 2012 